総 説

\title{
Macrosaccadic oscillations
}

\author{
小宮山 純
}

\section{Macrosaccadic oscillations}

\author{
Atsushi Komiyama \\ Department of Neurology, Hiratsuka Kyousai Hospital
}

\begin{abstract}
Several types of saccadic intrusions have their own salient features, including the presence, absence or latency of intersaccadic intervals. Macrosquare-wave jerks are known to have a shorter latency of about $100 \mathrm{msec}$, suggesting the involvement of the non-visually guided reflex saccade. Spuare-wave jerks and macrosaccadic oscillations (MSOs) are generally considered to have normal intersaccadic intervals of $200 \mathrm{msec}$ in the visually guided saccadic system. Conversely, Kase et al. documented a shorter latency of about $160 \mathrm{msec}$, indicating an increased gain in the corrective saccadic system in a patient with spinocerebellar degeneration and MSOs. Our recent electro-oculographic study also showed a mean intersaccadic interval of $129.5 \mathrm{msec}$ in a myasthenia gravis patient with edrophonium induced MSOs. This short latency is similar to that of corrective saccades, and is consistent with our understanding that MSOs are a form of saccadic hypermetria that is followed by a sequence of corrective saccades to attain the target.
\end{abstract}

Key words: macrosaccadic oscillations, saccadic hypermetria, saccadic intrusions, saccadic oscillations, intersaccadic intervals

\section{はじめに}

眼振が注視点からドリフトする緩徐相に異常が あるのに対して, saccadic intrusions（衝動性眼 球運動妨害) は不適切な衝動性眼球運動が注視時 やその変換時に生じる病態を指している。Saccadic intrusions は不適切な衝動性眼球運動全体 を含める場合1) と，散発例に限定し持続例には saccadic oscillations（衝動性眼球振動）と使い分 ける場合とがある2。Saccadic intrusions は極め てすばやく短時間に生じるため，その性状を理解 し背景にある異常を解析するためには電気眼振計 や磁気サーチ・コイルなどによる波形, 速度, in-

国家公務員共済連合会平塚共済病院神経内科 tersaccadic interval（運動と運動との間の眼位が 静止している期間）の定量的な計测が必須とな る。しかし，かかる検討はこれまで十分とはいえ ず1)，今後新事実が追記されてくるものと思われ る。本総説では, saccadic intrusions の現状理解 について簡単に触れたのちに，今回のテーマであ る macrosaccadic oscillations (MSOs) について われわれの知見3）を含めて解説する。

\section{Saccadic-intrusions $の$ 分類と性質}

Intersaccadic interval の有無やその持続時間な どの特徵から表 1 のよ5に分類されている。シ ェーマを図1に示した。

1. Square-wave jerks (Gegenrucke, 矩形波 眼球運動) 
表 1 Saccadic intrusions の特㞶

\begin{tabular}{|c|c|c|c|c|c|}
\hline & 振幅 ( $\left.{ }^{\circ}\right)$ & 持統 & 潜時 (msec) & 暗所 & 疾患 \\
\hline square-wave jerks & $0.5 \sim 5$ & 散発 ${ }^{a}$ & 200 & 出現 & 進行性核上性麻瘦、小脳疾患、健常者（閉眼時 \\
\hline quare-wave jerks & $20 \sim 40$ & 群発 & $50 \sim 150$ & 出現 & 多発性硬化症、多系統菱縮症 \\
\hline tacrosaccadic oscillations & $1 \sim 50$ & 群発 & 200 & 消失 & 小脳疾患急性期、重症筋無力症 \\
\hline accadic pulses & 記載（一） & 散発 & 無 & 出現 & 脳幹脳炎 \\
\hline ocular flutter & 記載（一) & 群発 & 無 & 出現 & 傍感染性脳炎、傍踵堚性神経障害 \\
\hline opsoclonus & 高振幅 & 群発 & 無 & 出現 & ocular flutterに同じ \\
\hline
\end{tabular}

a群発的に持続しsquare wave oscillationとなる場合もみられる゙。

固視点より一方向性に $2^{\circ}$ 以下 $\left(0.5 \sim 5^{\circ}\right)$ の 共同性水平性衝動性眼球運動が出現乙, 約 200 msec（指標に対する衝動性眼球運動 (visually guided saccade) の潜時に一致）の intersaccadic interval 後に逆方向への運動に上り元に戻る（図 1A) ${ }^{11}$ 。時に連続性となり square-wave oscillations と呼ばれる2)。進行性核上性麻痺や特定の小 脳疾患でよく観察されるが，健常人（ことに高齢 者）でも閉眼時に観察される。Square-wave

\section{A. Square wave jerks}

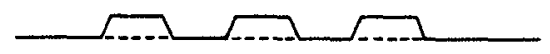

B. Macrosquare wave jerks

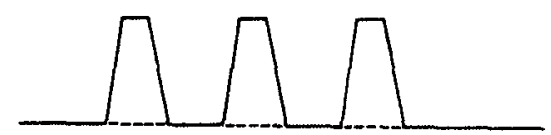

C. Macrosaccadic oscillations

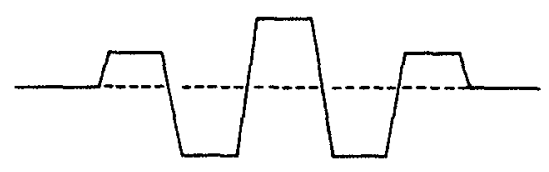

D. Saccdic pulses

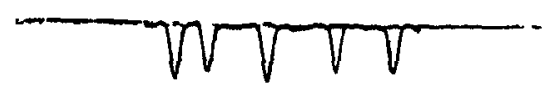

\section{E. Ocular flutter}

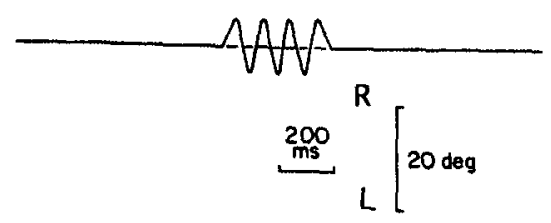

図 1 Saccadic intrusions 9 模式図 (文献 1 上り 改変) jerks の正確な機序は不明であるが，動物実験で はバースト細胞発火を抑制するポーズ細胞に直接 ・間接に影響している前頭葉眼球運動野, 上丘, 中脳網様体の不活化によって出現する1)。進行性 核上性麻㽻ではこれら上丘や中脳網様体が障害を 受ける。

2. Macrosquare-wave jerks（大矩形波眼球運 動)

指標から両眼が離れる大きな（通常 $5^{\circ}$ 以上） 衝動性眼球運動を生じ, 引き秸き 50〜150 msec の短い intersaccadic interval 後に反射性衝動性 運動によって元に戻る現象であり, 突発的に 2 $3 \mathrm{~Hz}$ で連続性に出現する（図 1 B $)^{1) 4) 5) 。 ~}$

最初の 2 報告4)5) は水平性であったが，垂直性も 報告されている6〉。注視によって振幅が增大し持 続が延びる。片眼遮蔽により軽減する場合（inverse latent) ${ }^{5)}$ がある。閉眼や暗所でりラックス すると消失するが， square-wave jerks 炕変化す る場合もある4。一方，閉眼下以イメージした指 標を思い浮かべるよう指示すると出現する4)。最 初の詳細な記載は小脳症状を有する多発性硬化症 患者)で行われた。発現機序は不詳である。

3. Macrosaccadic oscillations（巨大衝動性眼 球振動)

固視点を中心として主に左右に振動する巽常眼 球運動であり, その振幅 $\left(1 \sim 30^{\circ}\right)$ が増幅・減 衰する(図 1C) 1)3)。稀缍直方向に出現する6)。 Intersaccadic interval 注約 $200 \mathrm{msec}$ とされてき た1)。報告例のほとんどは暗所で消失する。小脳

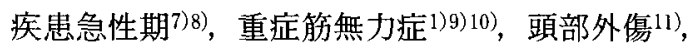
春髄小脳変性症6)12)で報告されている。小脳は衝 動性眼球運動を校正し安定させる働きをして括 り，その代償機転が障害されるために生じる。 Saccadic hypermetria 飞和计る衝動性眼球運動の 利得（眼球運動の振幅/刺激の振幅）が $1.0 \sim 2.0$ 
で生じるのに対して，MSOsでは2.0以上になる ためと解积される7) (図 2)。重症筋無力症に打け るエドロフォニウム誘発性 MSOsでは, 小脳病 変とは利得增大の場所に違いがあると理解されて いる10)。

4. Saccadic pulses (衝動性眼球運動律動)

固視点から離れる小さな衝動性眼球運動に引き 続き，急速にドリフトして戻る運動であり， intersaccadic interval を有しない。連続したり， double saccadic pulses の形をとる（図 1 D)。通 常水平性に舅察される。

5. Ocular flutter (眼球粗動), Opsoclonus (saccadomania, 眼球クローヌス)

Intersaccadic interval を有しない眼球振動であ り, ocular flutter は一方向（通常水平方向）に, opsoclonus 注水平, 垂直, 回旋の全要素からな る。Ocular flutter は問欠的に固視変換時に観察 され (図 $1 \mathrm{E}$ ), opsoclonus の軽症型と理解され る。持続性 opsoclonus は高振幅, 不規則, 反復 性, 多力向性の際立った眼球振動で, 固視を妨害 するが閉眼時ないし睡眠中にも持続する。Op-

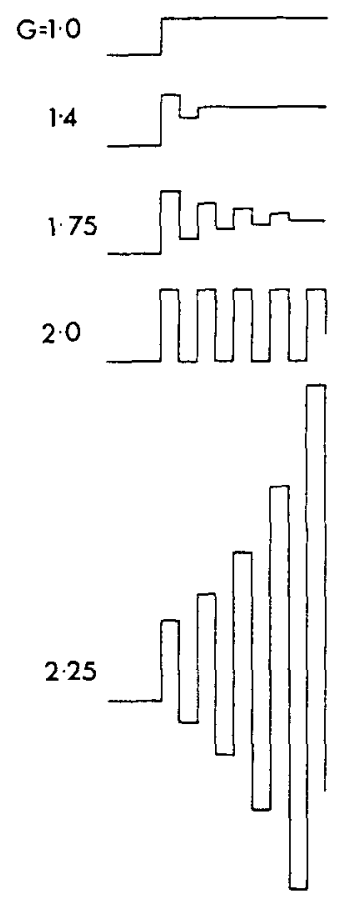

図2 種々の利得を呈する衝動性眼球運動のコン ピッーター・シュミレーション $\mathrm{G}=$ 利得。(文献 7 より改变) soclonus にミオクーヌス, 身震い様運動, 驚愕 反射, 小脳症状が加わると, opsoclonus-myoclonus syndrome 之称されウイルス感染後や肺癌, 乳癌, 卵巣癌による傍腫瘍性神経障害としてみら れる。小児発症例の半数以上は神経提由来の神経 芽腫が原因となる。

Square-wave jerks と異なり動物モデルはな い。伝統的に小脳病変との関連が示唆されてきた が定量的検討を欠いてきた。もら一つの考方方は 衝動性眼球運動を制御するポーズ細胞の障害があ る。ポーズ細胞の神経伝達物質はグリシン13)で あり,このグリシン拮抗薬のストリキニン処置に より opsoclonus とミオクローススが生じたこと が報告されている14)

\section{Macrosaccadic oscillations (MSOs)}

1. 歷史的背景

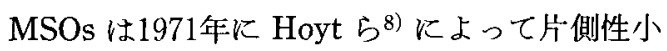
脳疾患急性期の 3 例で pendular macro-oscillations と乙て初めて報告された。水平方向の衝動 性眼球運動に引き続き, $50^{\circ}$ の高振幅で約 $1 \mathrm{~Hz}$ の眼球振動が生じ，閉眼により抑制された。小脳 症状発症後 2,3 週間に観察され, 以後 saccadic dysmetria に変化していった。定量的記載はな い。これまで類似の眼球振動がドイッで Kippdeviationen と報告されていたが，MSOs と異 なり注視で消失し閉眼で出現する特徵を有してい る)。

2. MSOs の定量的検討（表 2) と問題点

最初の定量的記載は1976年 Selhorst ら ${ }^{7)} に よ$ ってなされ，今日の MSOs 理解の基盤になって いる。4 例の小脳疾患（小脳虫部への転移性出血 性メラノーマ2 例, 小腷出血 1 例, 多発性硬化症 1 例）急性期に観察された。MSOs は, 共同性, 水平性, 対称性, $30 \sim 50^{\circ}$ の振幅で数秒間群発 し，注視変換ないし指標追跡によって誘発され た。閉眼で消失し，イメージ下に行ら schematic saccade/smooth pursuit では誘発されなかった。 1 例の定量的検討により，（1）衝動性眼球運動か

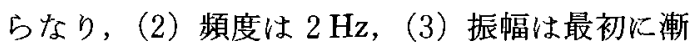
増次いで漸減し，(4) 衝動性眼球運動の開始の間

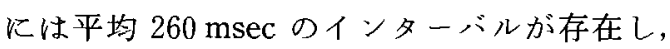
（5） intersaccadic interval 時に系統的なドリフト はみられなかった。これらの結果から, MSOs は visually guided saccadic system に括ける利得 
表 2 Macrosaccadic oscillations の定量的検討例

\begin{tabular}{|c|c|c|c|c|c|}
\hline 著者 & 発表年 & 基礎疾患 & $\begin{array}{c}\text { intersaccadic } \\
\text { interval (msec) }\end{array}$ & 振輻 & 方同 \\
\hline Selhorst 5 & 1976 & 小缕疾患急性期 & 約 $260^{\circ}$ & $\sim 40$ & 水平 \\
\hline Kase 5 & 1985 & 春骵小膎変性症 & $163(116 \sim 292)$ & $\sim 17.5$ & 水平 \\
\hline Averbuch-Heller 5 & 1996 & 頭部外偒 (橋病变) & $200(160 \sim 240)$ & $\sim 15.5$ & 水平 - 垂直 - 回旋 \\
\hline Komiyama 5 & 1999 & 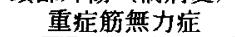 & $129.5(73 \sim 256)$ & $\sim 50$ & 水平 \\
\hline
\end{tabular}

a 衝動性眼球運動開始のインターバル（saccadic initiation interval）の測定值。

の増大と不安定が関与するものと解积した。この 論文以降, MSOs は square-wave jerks 同様指 骠に対する正常な衝動性眼球運動潜時（約 200 msec)を有する saccadic intrusions に分類される に至った ${ }^{1) 5)}$ 。 Averbuch-Heller ら ${ }^{11)} の$ MSOs 例 も，暗所で变化がないなど非典型的な側面を有す るが intersaccadic interval は 160 240 msec で めった。

一方, Kase 5 ${ }^{12)}$ 恃沗髄小脳変性症例にみられ た MSOs $の$ intersaccadic interval が平均 163 msec と短潜時で corrective saccades のそれに一 致することから, corrective saccadic system の 利得が立進した状態と考えた。彼らの例ではHoyt らの 3 例 8 之同様に MSOs が次第飞 saccadic hypermetria に変化し，これらの intersaccadic interval が同一であることを実証した。この結果 は, MSOsが一連の corrective saccadesにより 指標に至る saccadic hypermetria の一型 (利得 が2.0以上の）との従来の見解化一致している3。

このような展開を受けて, Selhorst ら7)のデー タを再検してみた。理由は不明でするが，彼らは intersaccadic interval ではなく衝動性眼球運動の 開始のインターバル（一つの衝動性眼球運動の持 続時間＋intersaccadic interval）を测定し, 平均 $260 \mathrm{msec}$ であり正常の衝動性眼球運動の分布に一 致すると結論した。しかし，彼らの例では眼球 運動速度が main sequence の振幅・最大速度特 性 ${ }^{15)}$ と比較すると50\%以下であった。すなわち $40^{\circ}$ の衝動性眼球運動速度が扣よそ $600^{\circ} /$ 秒15)で あることから，速くとも $300^{\circ} /$ 秒あるいはそれ 以下であったものと想定される。この速度で $\mathrm{MSOs}$ の平均振幅 $40^{\circ}$ 移動するのに必要な時間

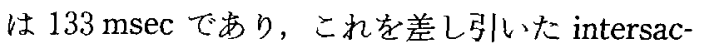
cadic interval は $127 \mathrm{msec}$ と計算される。この值 は，彼らが前報で算出した saccadic overshoot dysmetria $の$ intersaccadic interval $(125 \mathrm{msec})^{16)}$
や corrective saccades (125 msec) の潜時17) と近 似している。

一方, 重症筋無力症患者でェドロフォニウム注 射時に短時間 MSOs が発現することが簡単に 3 例1)910) で記載されていたが，定量的検討はなか った。そこで，上記の問題点を念頭に置きつつ， 末梢性眼笳麻痺に対する中枢による saccadic adaptation を理解する目的で，種々の状況下で エドロフォニウムを投与して眼球運動の定量的解 析を行った3)。

\section{重症筋無力症におけるエドロフォニウム誘発性} MSOs $の$ 定量的解析

\section{1 . 患者病歴}

57 歳女性。䄪 1 力月前から水平性複視と両眼瞼 下垂が出現し進行した。メスチノン $(180 \mathrm{mg} /$ 日) 反応せず当科を紹介され受診した。現症上，高度 の両眼瞼下垂と眼球運動制限があり，両眼ともに 水平方向には $10^{\circ}$ を超えず，上方視は完全に麻 痺していたが，下方には約 $30^{\circ}$ の動きが可能で あった。高度の外眼筋麻瘏にかかわらず，すばや い小さな両眼球の動さが眼瞼挙上時や注視変換時 に観察された (quiver movement)。大きな衝動 性眼球運動を行わせると最初は急速であるが，途 中から速度が減衰し，ゆっくりと目標に到着し た。閉眼力を含めそのほかの筋力低下は明らかで なかった。検査上, テンンロン試験（エドロフォ ニウム $10 \mathrm{mg}$ 投与）により両眼瞼下垂は消失し, MSOs が生じた。眼輪筋の反復刺激試験で重症 筋無力症として典型的な減衰現象がみられ，抗 $\mathrm{AChR}$ 抗体価は $22 \mathrm{nmol} / \mathrm{L}$ と上昇していた。胸 部 CT 上前縦隔に胸腺腫が確認された。ステロ イド投与と胸腺摘除に上る症状の回復とともに， quiver movementはみられなくなりエドロフォ ニウムにより MSOs は誘発されなくなった。

2. 神経耳科学的解析

眼球の水平・垂直運動を $\mathrm{AC}$ 電気眼振計（時 
定数：原波形記録 $1.6 \mathrm{sec}$, 速度波形 $0.02 \mathrm{sec}$ ) とビデオを用いて記録した。その結果，（1） $10^{\circ}$ 本平性衝動性眼球運動は目標を超えて hypermetricで,ドリフトして戻った (quiver movement) (図 $3 \mathrm{~A})$ 。（2）エドロフォニウム投与 20 秒ほど で，指標に従って運動することが困難となり，
MSOs を生じた（図 $3 \mathrm{~B}$ )。頻度は 2 3 Hz, 最 大振幅は $50^{\circ}$, 約 2 分で減弱・消失した。正面注 視時にエドロフォニウムを投与しても MSOs は 生じるが低振幅であった。（3）閉眼や非注視下 (Frenzel 眼鏡) では MSOs が著明に抑制され, 極めて低振幅となった（図 $3 \mathrm{C}$, 矢印)。開眼に
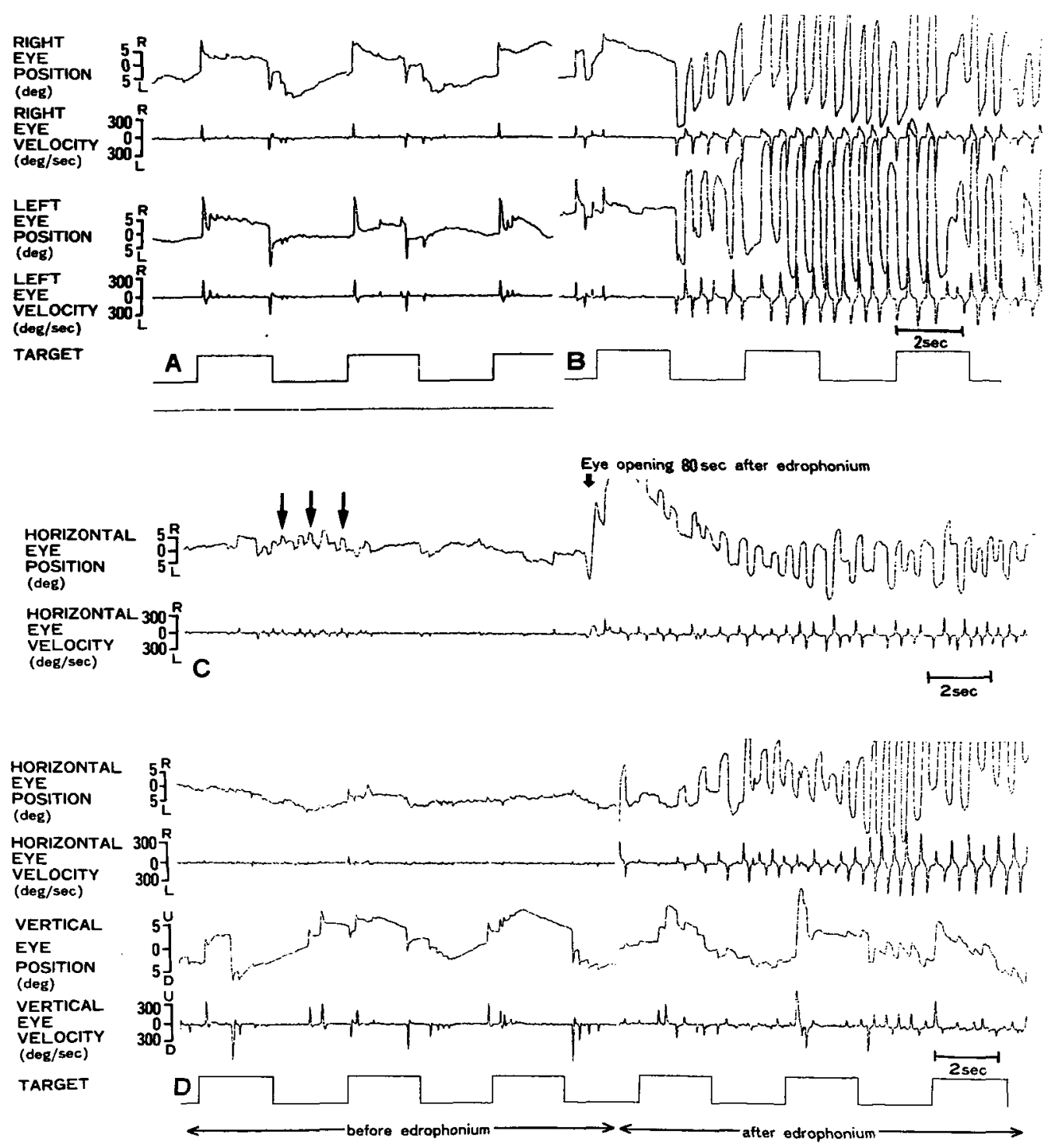

图 3 MSOs の電気眼振図

$10^{\circ}$ の水平性衝動性眼球運動時に quiver movement (A) が明らかで, エドロフォニウム静注20秒 後から MSOs (B) が出現した。閉眼時にェドロフォニウムを注射するとMSOsは抑制された (C，矢印）。80秒後に閶眼すると MSOs が突然出現した。垂直性衝動性眼球運動時にエドロフォ ニウムを投与すると，水平性 MSOs が重畳した（D）。（文献 3 より改変） 


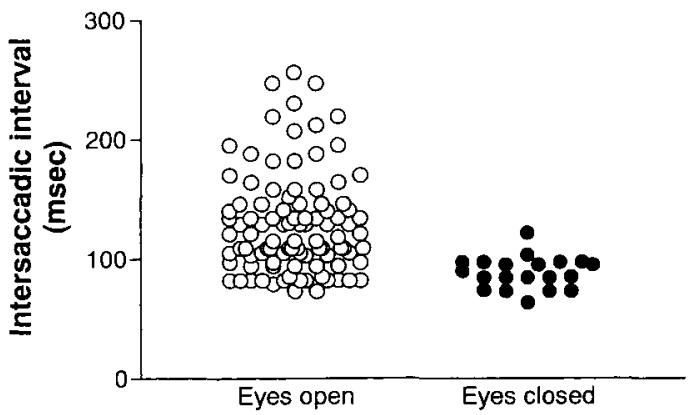

図 4 開眼時 (白丸) と閉眼時 (黒丸) 時の MSOs $の$ intersaccadic interval (文献 3 より引用)

より突如 MSOsを生じた（図 3 C)。（4）垂直性 衝動性眼球運動施行時にエドロフォニウムを投与 すると，水平性 MSOs が重畳した（図 $3 \mathrm{D}$ )。（5） 電気眼振図を強拡大乙て intersaccadic interval を測定する゙）と，129.5 msec（73〜253 msec）で

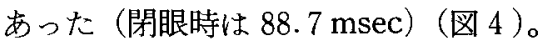

\section{3. 考察}

筋無力症性眼筋麻疩を是正しょうとして中枢は 代償的に saccade pulse のサイズを大きくしてい る。この時点でェドロフォニウムを投与すると神 経筋ブロックが一時的に解除されるために，代償 性中权性変化が表面化するるのと考光られる。衝 動性眼球運動の利得がえ進しているため saccadic hypermetria を生じることになるが，利得が 2.0 以上の場合には指標を中心と乙て左右に動く衝動 性眼球運動が出現するものと理解される（図 2)。

今回の検討から，代償性に生じた saccade pulse の増大は複視による網膜エラー信号が引き 金となって表面化するものと考兄られた。恐らく 複視の程度が大となるために，水平性注視変換時 の方が正面注視時より saccadic pulse のサイズが 大きくなり，結果として著明な MSOs に至った ものと考光た。しかし，閉眼でも小さな MSOs が出没したことから，非注視下でもリークするる のと思われた。

MSOs $の$ intersaccadic interval は平均 129.5 msec であり, corrective saccades のそれに近似 乙 visually-guided saccade system $の$ 平均潜時 200 msec より短かかった。このことは, 本例にみら れたエドロフォニウム誘発性 MSOs が反射性衝 動性運動を介する異常眼球運動であることを示唆
している。

垂直性衝動性眼球運動施行時にメドロフォニウ ムを投与したところ，水平性 MSOs が重畳した。 この結果は, 高度の垂直方向の制限に抗して眼球 運動を行わせても，中权による代償は水平性眼球 運動を改善する方向でプリセットされていること を示している。末梢性眼筋麻痺に対して中枢性代 償が発現するまでには数日を有することが知られ ている18)ことから，患者自身が水平性衝動性運 動を用いて注視変換を行っていたことが主な要因 と考光た。

\section{まとめ}

Saccadic intrusions の解析火は眼球運動の定量 的解析が必要となるが，現在の定説が必ずしも十 分なデータの蓄積に基づくものではないことを指 摘した。今回の MSOsに関しても，これまで主 に一報告の結果から visually guided saccade の 正常潜時 $200 \mathrm{msec}$ を有するものと理解されてき た。しかし, 今回の検討から MSOsが一連の corrective saccades (通常潜時 $125 \mathrm{msec}$ )により 指標に到達する saccadic hypermetria の一型(利 得2.0以上の）であるとの認識に一致して, 反射 性衝動性眼球運動を介する場合のあることを指摘 した。

文献

1) Leigh RJ, Zee DS: The neurology of eye movements. 3rd ed. pp 449-456, FA Davis, Philadelphia, 1999

2 ) Abel LA, Traccis S, Dell'Osso LF, et al: Square wave oscillation. The relationship of saccadic intrusions and oscillations. Neuroophthalmology 4: 21-25, 1984

3 ) Komiyama A, Toda H, Johkura K: Edrophonium-induced macrosaccadic oscillations in myasthenia gravis. Ann Neurol 45: 522525, 1999

4 ) Dell'Osso LR, Troost BT, Daroff RB: Macro square wave jerks. Neurology 25: 975-979, 1975

5 ) Dell'Osso LF, Abel LA, Daroff RB: "Inverse latent" macro square-wave jerks and macro saccadic oscillations. Ann Neurol 2: 57-60, 1977

6) Fukazawa T, Tashiro K, Hamada T, et al: 
Multisystem degeneration: drugs and square wave jerks. Neurology 36: 1230-1233, 1986

7 ) Selhorst JB, Stark L, Ochs AL, et al: Disorders in cerebellar ocular motor control. II . Macrosaccadic oscillation. An oculographic, control system and clinico-anatomical analysis. Brain 99: 509-522, 1976

8 ) Hoyt WF, Daroff RB: Supranuclear disorders of ocular motor control systems in man. Clinical, anatomical, and physiological correlations-1969. In eds Bach-y-Rita P, Collins $\mathrm{CC}$, Hyde JE. The control of eye movements. pp 175-235, Academic Press, New York, 1971

9) Schmidt D, Dell'Osso LF, Abel LA, et al: Myasthenia gravis: dynamic changes in saccadic waveform, gain, and velocity: Exp Neurol 68: 365-377, 1980

10) Abel LA, Dell'Osso LF, Schmidt D, et al: Myasthenia gravis: analog computer model. Exp Neurol 68: 378-389, 1980

11) Averbuch-Heller L, Kori AA, Rottach KG, et al: Dysfunction of pontine omnipause neurons causes impaired fixation: macrosaccadic oscillations with a unilateral pontine lesion. Neuro-ophthalmology 16: 99-106, 1996

12) Kase M, Nagata R, Arikido T: Macrosaccadic oscillation, saccadic dysmetria and motor error in spinocerebellar degeneration. Jpn J
Ophthalmol 29: 369-377, 1985

13) Horn AKE, Büttner-Ennever JA, Wahle $P$, et al: Neurotransmitter profile of saccadic omnipause neurons in nucleus raphe interpositus. J Neurosci 14: 2032-2046, 1994

14) Blain PG, Nightingale $S$, Stoddart JC, et al: Strychnine poisoning: abnormal eye movements. J Toxicol Clin Toxicol 19: 215-217, 1982

15) Bahill AT, Clark MR, Stark L: The main sequence, a tool for studying human eye movements. Math Biosci 24: 191-204, 1975

16) Selhorst JB, Stark L, Ochs AL, et al: Disorders in cerebellar ocular motor control. I . Saccadic overshoot dysmetria. An oculographic, control system and clinico-anatomical analysis. Brain 99: 497-508, 1976

17) Weber RB, Daroff RB: Corrective movements following refixation saccades: type and control system analysis. Vision Res 12 : 467-475, 1972

18) Abel LA, Schmidt D, Dell'Osso LF, et al: Saccadic system plasticity in humans. Ann Neurol 4: 313-318, 1978

$\left(\begin{array}{l}\text { 原稿到着 : 平成13年 } 5 \text { 月22日 } \\ \text { 別刷請求先：小宮山純 } \\ \text { 干254-8502 神奈川県平塚市追分9-11 } \\ \text { 国家公務員共済連合会平堟共済病院 神経内科 } \\ \text { E-mail: komiyama@kkr.hiratsuka.kanagawa.jp }\end{array}\right)$

